\title{
Influence of the Component Excipients on the Quality and Functionality of a Transdermal Film Formulation
}

\author{
Suprit D. Saoji, ${ }^{1}$ Sandip C. Atram, ${ }^{2}$ Pradip W. Dhore, ${ }^{1}$ Priya S. Deole, ${ }^{3}$ Nishikant A. Raut, ${ }^{1}$ and Vivek S. Dave ${ }^{4,5}$
}

Received 23 February 2015; accepted 8 April 2015; published online 29 April 2015

\begin{abstract}
The influence of formulation variables, i.e., a hydrophilic polymer (Methocel ${ }^{\circledR}$ E15) and a filmforming polymer (Eudragit ${ }^{\circledR}$ RL 100 and Eudragit ${ }^{\circledR}$ RS 100), on the physicochemical and functional properties of a transdermal film formulation was assessed. Several terpenes were initially evaluated for their drug permeation enhancement effects on the transdermal film formulations. D-Limonene was found to be the most efficient permeation enhancer among the tested terpenes. Transdermal film formulations containing granisetron (GRN) as a model drug, D-limonene as a permeation enhancer, and different ratios of a hydrophilic polymer (Methocel ${ }^{\circledR}$ E15) and a film-forming polymer (Eudragit ${ }^{\circledR}$ RL 100 or Eudragit ${ }^{\circledR}$ RS 100) were prepared. The prepared films were evaluated for their physicochemical properties such as weight variation, thickness, tensile strength, folding endurance, elongation (\%), flatness, moisture content, moisture uptake, and the drug content uniformity. The films were also evaluated for the in vitro drug release and ex vivo drug permeation. The increasing ratios of Methocel ${ }^{\circledR}:$ Eudragit ${ }^{\circledR}$ polymers in the formulation linearly and significantly increased the moisture content, moisture uptake, water vapor transmission rate (WVTR), and the transdermal flux of GRN from the film formulations. Increasing levels of Methocel ${ }^{\circledR}$ in the formulations also increased the rate and extent of the GRN release and the GRN permeation from the prepared films.
\end{abstract}

KEY WORDS: film-forming polymers; hydrophilic polymers; permeation enhancers; transdermal films.

\section{INTRODUCTION}

The transdermal drug delivery can no longer be considered a "novel" drug delivery technology. Over the past few decades, there has been a tremendous growth in the understanding of the technology involved in the development of transdermal drug delivery systems (TDDS). TDDS are designed to deliver the drug(s) across the skin at a controlled rate into the systemic circulation. TDDS offers several, welldocumented advantages over the conventional oral and parenteral routes of drug delivery (1-3). These include therapeutic advantages such as sustained delivery of drugs, avoiding pre-systemic metabolism, avoiding hostile gastrointestinal factors (e.g., gastric $\mathrm{pH}$, gastric transit time, etc.), suitability for drugs with short biological half-life and narrow therapeutic index, and relatively lower fluctuations observed in the drug plasma levels. Some of the patient compliance benefits include non-invasive drug administration, flexibility in the dosing frequency, suitability for self-medication, and better control of

\footnotetext{
${ }^{1}$ Department of Pharmaceutical Sciences, R. T. M. Nagpur University, Nagpur, India.

${ }^{2}$ Vidyabharati College of Pharmacy, Amravati, India.

${ }^{3}$ G. S. Tompe College, Chandurbazar, Amravati, India.

${ }^{4}$ St. John Fisher College, Wegmans School of Pharmacy, 3690 East Avenue, Rochester, New York 14618, USA.

${ }^{5}$ To whom correspondence should be addressed. (e-mail: viveksdave@gmail.com)
}

the side effects/adverse effects. TDDS are also associated with uncommon limitations such as suitability limited to potent (low dose) drugs, stratum corneum as a barrier to drug absorption, requirement of the ideal permeability characteristics of the drugs, non-suitability for tolerance-inducing drugs, and costly nature of the dosage form $(1,4,5)$. Nevertheless, several transdermal formulations consisting of drugs over a range of pharmacological classes are approved to be marketed in the USA or are in different stages of development $(4,5)$. The TDDS market is reported to be worth $\$ 12.7$ billion in 2005 and is anticipated to be over $\$ 30$ billion this year (2015) (4).

Stratum corneum, being a natural protector, limits the penetration of the xenobiotics. It is known to be a major rate-limiting factor to the transdermal absorption of a drug and its subsequent systemic bioavailability (6). The role of permeation enhancers in the formulation of transdermal systems was envisaged early on to overcome the challenge of limited transdermal absorption of a drug $(7,8)$. Permeation enhancers originating from a wide variety of chemical classes, including alcohols, fatty acids, amines, esters, amides, hydrocarbons, surfactants, etc., have been explored to enhance the transdermal absorption of the drugs (9). The permeation enhancers act mainly by disrupting the lipid bilayers within the stratum corneum (10). The disruption of the natural integrity of the stratum corneum is known to cause skin irritation, and thus, a rational selection of a permeation enhancer that enhances the drug permeation through the skin with minimal alteration of the structure and functions of the skin is of 
critical importance (11). Terpenes are naturally occurring volatile oils that have gained popularity in the recent years as choice enhancers in transdermal formulations (12). Terpenes are also known to be versatile in their applications, i.e., they are suitable for the percutaneous penetration and absorption enhancement of both hydrophilic and lipophilic drugs $(13,14)$. Moreover, compared with surfactants and other permeation enhancers, terpenes, when used in lower concentrations, exhibit relatively lower percutaneous irritancy (15).

Other key components of transdermal formulations apart from the permeation enhancers include the filmforming polymers and one or more hydrophilic polymers incorporated as rate-controlling matrix formers (16-18). These excipients are available in a wide range of physicochemical properties and grades. The nature and the amount of these excipients incorporated in a TDDS can have a significant influence on the manufacturability, quality, and performance of the final drug product. Most of the studies report the incorporation of a variety of these excipients in the formulation of transdermal delivery systems (19-21). However, the studies that evaluate the influence of these formulation variables in a systematic, quantitative manner are few and far between.

The present investigation was aimed at quantitatively and systematically assessing the influence of the ratio of two formulation variables, i.e., a hydrophilic polymer and a film-forming polymer, on the physicochemical and functional attributes of transdermal films. The study was carried out in three stages. First, several terpenes were evaluated for their permeation-enhancing efficiency across the excised hairless rat skin. Granisetron (GRN) was chosen as a model drug for this study. The physicochemical properties of GRN allow it to be incorporated into a transdermal drug delivery system. These properties include low molecular mass, high lipid solubility, low therapeutic dose, as well as a high degree of first-pass metabolism. Next, several transdermal film formulations containing different ratios of a hydrophilic polymer $\left(\right.$ Methocel $\left.^{\circledR} \mathrm{E} 15\right)$ and a film-forming polymer (Eudragit ${ }^{\circledR}$ RL 100 or Eudragit ${ }^{\circledR}$ RS 100) were prepared. Finally, the prepared films were evaluated for their physical, chemical, in vitro drug release, and ex vivo drug permeation properties. The results were statistically analyzed to understand the influence of these formulation variables on the prepared films.

\section{MATERIALS AND METHODS}

\section{Materials}

Granisetron samples were obtained from Wockhardt Limited (India). Hydroxypropyl methycellulose (Methocel ${ }^{\circledR}$ E15) was obtained from Colorcon Asia Pvt. Ltd. (India). Eudragit $^{\circledR}$ RL 100 and Eudragit ${ }^{\circledR}$ RS 100 were obtained from Evonik Degussa India Pvt. Ltd. (India). Eugenol and D-limonene were obtained from Keva Fragrances Ltd. (India). $\alpha$-Terpineol and menthol were obtained from Workwell (India). ScotchPak 1109 backing membrane was obtained from 3M Drug Delivery Systems, USA. Other solvents and reagents used were of analytical grade.

\section{Methods}

Preparation of Biological Membrane for Permeability Studies

Ethical clearance for the handling of experimental animals was obtained from the institutional animal ethics committee (IAEC) formed for this purpose. Male Sprague Dawley ${ }^{\circledR}$ rats weighing 200 to $250 \mathrm{~g}$ were euthanized by cervical dislocation, and the dorsal skin was removed. After removing the epidermal hair and the subcutaneous fat, the skin was thoroughly washed with phosphate-buffered saline (PBS, pH 7.4) and placed overnight in contact with the receptor phase, i.e., fresh PBS, $\mathrm{pH}$ 7.4. The overnight-stored rat skin was used for ex vivo permeability studies.

\section{Effect of Penetration Enhancers on Permeation of Granisetron}

The ex vivo permeation studies were carried out in a Franz diffusion cell with a diffusion surface area of $2.5 \mathrm{~cm}^{2}$. The biological membrane, with the stratum corneum facing the donor segment, was affixed to the diffusion cell. GRN solution (1 mg/ml, in PBS, pH 7.4) was placed in the donor compartment containing D-limonene $(5 \% v / v)$, $\alpha$-terpineol $(5 \% v / v)$, eugenol $(5 \% v / v)$, or menthol $(5 \% v / v)$. The absence of penetration enhancer served as a control. The receiver compartment contained magnetically stirred PBS (18 ml, pH 7.4), maintained at $37 \pm 0.5^{\circ} \mathrm{C}$. The amount of drug permeated through the biological membrane was determined by analyzing the drug concentration in the filtered samples $(1 \mathrm{ml})$, withdrawn at predetermined time intervals. The samples were analyzed using a modified reverse-phase HPLC at a wavelength of $305 \mathrm{~nm}$. The cumulative amount (\%) of drug permeated was plotted against time.

\section{Permeation Data Analysis}

The drug concentration in the permeate was corrected for sampling effects according to the equation described by Hayton et al. (Eq. (1)) (22):

$C_{n}^{\prime}=C_{n}\left(\frac{V_{\mathrm{T}}}{V_{\mathrm{T}}-V_{\mathrm{s}}}\right)\left(\frac{C_{n-1}^{\prime}}{C_{n-1}}\right)$

where $C_{n}^{\prime}$ is the corrected concentration of the $n$th sample, $C_{n}$ is the measured concentration of GRN in the $n$th sample, $C_{n-1}$ is the measured concentration of the GRN in the $(n-1)$ th sample, $V_{\mathrm{T}}$ is the total volume of the receiver fluid, and $V_{\mathrm{s}}$ is the volume of the sample drawn. The steady-state flux $\left(J_{\mathrm{ss}}\right)$ and the permeability coefficient $\left(K_{\mathrm{p}}\right)$ were calculated using Eqs. (2) and (3), respectively, as described by Barry (23):

$J_{\mathrm{ss}}=\left(\frac{d Q}{d t}\right)_{\mathrm{ss}} \times \frac{1}{A}$

$K_{\mathrm{p}}=\frac{J_{\mathrm{ss}}}{C_{\mathrm{s}}}$

where $A$ is the effective diffusion area, $C_{\mathrm{s}}$ is the concentration in the saturated solution, and $\left(\frac{d Q}{d t}\right)_{\mathrm{ss}}$ is the steady-state slope. The penetration-enhancing effect of the terpenes was 
calculated as enhancement ratio (ER), using the following equation (Eq. (4)) (12):

$\mathrm{ER}=\frac{K_{\mathrm{P}}(\text { with penetration enhancer })}{K_{\mathrm{P}}(\text { without penetration enhancer })}$

\section{Drug-Polymer Compatibility Studies}

The preliminary physicochemical compatibility between GRN and the polymers used in the films was evaluated using differential scanning calorimetry (DSC) and the Fourier transform infrared (FTIR) spectroscopy.

Differential Scanning Calorimetry. The thermal analysis of GRN, the pure polymers, and their physical mixtures with GRN was carried out using a differential scanning calorimeter (Model: Q10, TA Instruments, Inc., New Castle, DE, USA). The analysis was done under a purge of dry nitrogen gas $(50 \mathrm{ml} / \mathrm{min})$. High-purity indium was used to calibrate the heat flow and the heat capacity of the instrument. The samples $(2.5-5 \mathrm{mg})$ were sealed in aluminum pans with the lids using a crimper. Each sample was subjected to a single heating cycle from 25 to $400^{\circ} \mathrm{C}$ at a heating rate of $10^{\circ} \mathrm{C} / \mathrm{min}$. The results were analyzed using the Universal Analysis software version 4.5A, build 4.5.0.5 (TA Instruments, Inc., New Castle, DE, USA).

Fourier Transform Infrared Spectroscopy. The infrared spectra of GRN, the polymers, and their physical mixtures with GRN were obtained from an FTIR spectrophotometer (Model: IR Prestige-21, Shimadzu, Japan) equipped with an attenuated total reflectance (ATR) accessory. The analysis of the samples was carried out using diffuse reflectance spectroscopy (DRS)-FTIR with $\mathrm{KBr}$. The influence of the residual moisture was theoretically removed by subjecting the samples to vacuum drying before obtaining any spectra. Each sample analysis included 45 scans, at a resolution of $4 \mathrm{~cm}^{-1}$ from 4000 to $600 \mathrm{~cm}^{-1}$.

Preparation and Characterization of Granisetron Transdermal Films

As shown in the Table I, ten matrix-type transdermal film formulations containing GRN, Methocel ${ }^{\circledR}$ E15, and Eudragit $^{\circledR}$ RL 100 or Eudragit ${ }^{\circledR}$ RS 100 were prepared. The preparation method as described previously by Kusum Devi et al. was followed (17). Briefly, the drug and the polymers, propylene glycol (plasticizer), and Dlimonene (penetration enhancer) were dispersed in ethanol (casting solvent), and the polymeric dispersion was degassed by sonication. The polymeric dispersion of the drug was then poured into a circular well formed by a glass mold $\left(5.68 \mathrm{~cm}^{2}\right.$, fabricated in the laboratory for the purpose), placed in a standard Petri dish containing mercury (Fig. 1). The rate of solvent evaporation was qualitatively controlled by covering the mold with an inverted funnel. The dry films were obtained after the evaporation of the casting solvent overnight in a solvent hood. The dried formulation films were carefully cut into uniform sizes to contain a theoretical equivalent of $\sim 4 \mathrm{mg}$ of the drug per film. This dose of GRN (4 mg per film) was targeted based on the recommended therapeutic doses of GRN for chemotherapy-induced nausea and vomiting (24). Preliminary studies based on film dimensions showed that GRN $(9.1 \% w / w)$ in the formulations achieved this target dose per film. A backing membrane was attached to the prepared films, and the films were stored in a desiccator, between the sheets of glassine paper.

\section{Evaluation of Physicochemical Properties of Films}

Weight Variation. The weight variation of the prepared films was evaluated by individually weighing three randomly selected films of each prepared formulation. The mean weight and the standard deviation for each formulation film were calculated and recorded.

Thickness. The thickness of prepared films was measured using a digital micrometer screw gauge with a least count of $0.001 \mathrm{~mm}$ (Mitutoyo, Japan) at three different locations on the film. Three randomly selected films of each formulation were evaluated for thickness. The mean thickness ( $\mathrm{mm})$ and the standard deviation for each formulation film were calculated and recorded.

Tensile Strength. The mechanical properties of the prepared polymer films were determined by measuring their tensile strength as described previously by Yener et al. (25). According to the American Society for Testing and Materials (ASTM), the tensile strength of polymeric films is a measure of the minimum stretching force applied to the sample that results in the breaking of the film. The tensile strength measurements were carried out on dumbbell-shaped films $(2.5 \times 1 \mathrm{~cm})$. The formulation films were subjected to a pulling force by hanging standard weights from the films and measuring the force $\left(\mathrm{kg} / \mathrm{mm}^{2}\right)$ using a load cell.

Percentage Elongation. The determination of longitudinal strain (percentage elongation at break) was carried out as described by Khanna et al. (26). The percentage elongation at break for the film samples was calculated using the following formula (Eq. (5)):

$\%$ elongation at break $=\frac{\text { increase in length }}{\text { initial length }} \times 100$

Folding Endurance. The folding endurance was evaluated by repeatedly folding a small strip of film $\left(2.5 \mathrm{~cm}^{2}\right)$ at the same location to the point of breaking (17). The folding endurance value is typically described as the number of times a film may be folded at the same 
Table I. Composition of the Transdermal Films

\begin{tabular}{|c|c|c|c|c|c|c|c|c|c|c|}
\hline \multirow[b]{2}{*}{ Formulation } & \multicolumn{10}{|c|}{ Composition $(\% w / w)$} \\
\hline & $\mathrm{F} 1$ & $\mathrm{~F} 2$ & $\mathrm{~F} 3$ & F4 & F5 & F6 & F7 & F8 & F9 & F10 \\
\hline Granisetron & 9.1 & 9.1 & 9.1 & 9.1 & 9.1 & 9.1 & 9.1 & 9.1 & 9.1 & 9.1 \\
\hline Methocel ${ }^{\circledR}$ E15 & 72.7 & 54.5 & 45.5 & 36.4 & 18.2 & 72.7 & 54.5 & 45.5 & 36.4 & 18.2 \\
\hline Eudragit $^{\circledR}$ RL 100 & 18.2 & 36.4 & 45.5 & 54.5 & 72.7 & 0.0 & 0.0 & 0.0 & 0.0 & 0.0 \\
\hline Eudragit $^{\circledR}$ RS 100 & 0.0 & 0.0 & 0.0 & 0.0 & 0.0 & 18.2 & 36.4 & 45.5 & 54.5 & 72.7 \\
\hline Propylene glycol $^{a}$ & 25.0 & 25.0 & 25.0 & 25.0 & 25.0 & 25.0 & 25.0 & 25.0 & 25.0 & 25.0 \\
\hline D-Limonene ${ }^{b}$ & 5.0 & 5.0 & 5.0 & 5.0 & 5.0 & 5.0 & 5.0 & 5.0 & 5.0 & 5.0 \\
\hline
\end{tabular}

${ }^{a}$ Quantity represents $\% w / w$ of the total polymer weight

${ }^{b}$ Quantity represents $\% w / w$ of the total polymer weight

location before it breaks. Three randomly selected samples of each prepared formulation film were evaluated for the folding endurance. The mean and the standard deviation for each formulation were calculated and recorded.

Drug Content Uniformity. The GRN content was assayed on ten randomly selected films from each formulation. The prepared films were dissolved in ethanol $(2 \mathrm{ml})$, and the volume was adjusted to $100 \mathrm{ml}$ with PBS ( $\mathrm{pH}$ 7.4). The solution was filtered and suitably diluted, and the GRN content of each film was determined using a modified reverse-phase HPLC (RP-HPLC) method previously described by Pinguet et al. (27). Briefly, the HPLC system (Model: Prominence, Shimadzu Corporation, Kyoto, Japan) with LCsolution software, equipped with a LC-20AD HPLC pump, a manual rheodyne sample injector, and a SPD-M20A detector, was used. The mobile phase was composed of methanol/0.02 M phosphate buffer $(\mathrm{pH} 4.0)(40: 60, v / v)$, at a flow rate of $1 \mathrm{ml} / \mathrm{min}$. A Hypersil-Keystone C-18 column $(250 \times 4.6 \mathrm{~mm}, 5 \mu \mathrm{m})$ was used as a stationary phase, and the GRN samples were detected by ultraviolet (UV) detection at $305 \mathrm{~nm}$. The calibration of the peak area against concentration of GRN was found to be $y=10,498 x-73.42$ with $R^{2}=0.9997$ for the GRN concentration range of $2-10 \mu \mathrm{g} / \mathrm{ml}$ (where $y=$ peak area and $x=$ GRN concentration), and the limit of detection was found to be $0.02 \mu \mathrm{g} / \mathrm{ml}$.

Flatness. A method previously described by Kshirsagar et al. was used to calculate the flatness of the prepared films (20). Briefly, the prepared films were cut into uniform longitudinal strips. The length of each strip was then measured accurately, and the variations in length due to the non-uniformity of flatness were measured. The flatness of the strips was calculated by measuring the percent constriction using Eq. (6). A constriction value of $0 \%$ was assumed to indicate $100 \%$ flatness. Three randomly selected films of each formulation were evaluated for flatness. The mean and the standard deviation values for each formulation were calculated and recorded:

$\%$ Constriction $=\frac{l_{1}-l_{2}}{l_{2}} \times 100$

Percent Moisture Content. Three randomly selected films of each prepared formulation were marked, then weighed individually, and placed in a desiccator at room temperature $\left(25 \pm 0.5^{\circ} \mathrm{C}\right)$. The films were then removed and weighed at predetermined intervals until a constant weight was achieved. The moisture content ( $\%$ ) was calculated as a difference between the initial and the final weight with respect to the final weight (Eq. (7)) (28). The mean and the standard deviation values for each formulation were calculated and recorded.

$\%$ moisture content $=\frac{\text { final wt. }- \text { initial wt. }}{\text { initial wt. }} \times 100$

Percentage Moisture Uptake. The physical stability and the integrity of the polymeric films in humid environments
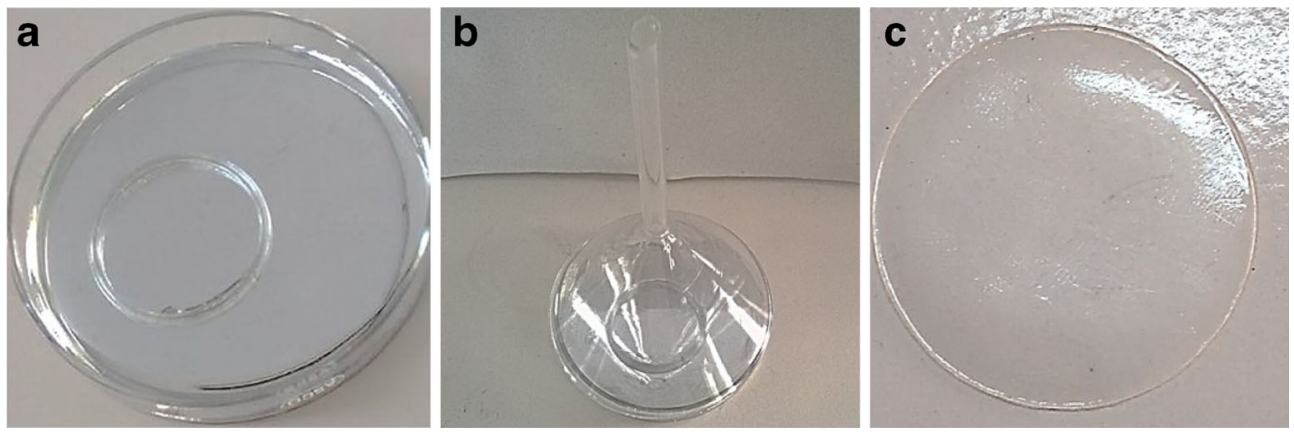

Fig. 1. Preparation of GRN films. a Circular glass mold in a Petri dish filled with mercury, b Mold covered with an inverted funnel to qualitatively control solvent evaporation, and c Dried GRN film 
are typically evaluated by calculating the percent moisture absorption at elevated humidity conditions.

The extent of moisture uptake by the prepared films at elevated humidities and at room temperature $(25 \pm$ $0.5^{\circ} \mathrm{C}$ ) was determined using the method described by Kusum Devi et al. (17). Briefly, saturated solutions of ammonium dihydrogen phosphate $(60 \pm 5 \% \mathrm{RH})$, sodium chloride $(75 \pm 5 \% \mathrm{RH})$, and potassium nitrate $(90 \pm 5 \%$ $\mathrm{RH})$ were placed in three separate desiccators respectively and allowed to equilibrate for $24 \mathrm{~h}$ to attain the respective humidity values (29). Three randomly selected films from each formulation were weighed and placed in each desiccator. The films were then removed at predetermined intervals and carefully weighed, until a constant weight was achieved (17). The percentage moisture uptake by the films was calculated using Eq. (8):

$\%$ moisure uptake $=\frac{\text { final wt. }- \text { initial wt. }}{\text { initial wt. }} \times 100$

Water Vapor Transmission Rate. The water vapor transmission rate (WVTR) is the amount of moisture transmitted through a unit area of film in a given duration at room temperature $\left(25 \pm 0.5^{\circ} \mathrm{C}\right)$. The WVTR for the prepared films was calculated using a method reported earlier (17). Briefly, glass cells were filled with $2 \mathrm{~g}$ of anhydrous calcium chloride, and a formulation film of specified area was affixed onto the cell rim. The cells were accurately weighed and placed in desiccators containing saturated solutions of ammonium dihydrogen phosphate $(60 \pm 5 \% \mathrm{RH})$, sodium chloride $(75 \pm 5 \% \mathrm{RH})$, or potassium nitrate $(90 \pm 5 \% \mathrm{RH})$, respectively (29). The glass cells were removed from the desiccators at regular intervals and weighed accurately. The process was continued until a constant weight was achieved. The amount of water vapor transmitted was determined using the formula below (Eq. (9)):

$\mathrm{WVTR}=\frac{\text { final weight }- \text { initial weight }}{\text { area } \times \text { time }}$

\section{In Vitro Release Studies}

The in vitro release of GRN from the prepared formulation films was determined using a Franz diffusion cell. Three randomly selected films of each formulation were used for the analysis of drug release from the prepared films. The film, supported with a backing membrane, was placed in the donor compartment of the cell. The donor compartment was separated from the receptor compartment by a dialysis membrane $\left(\right.$ Himedia $\left.^{\circledR}\right)$, with a molecular weight cutoff between 12,000 and 14,000 . The dialysis membrane was previously stored in PBS ( $\mathrm{pH} 7.4$ ) for $24 \mathrm{~h}$. The receptor compartment contained magnetically stirred PBS (18 ml, pH 7.4) maintained at $37 \pm$ $0.5^{\circ} \mathrm{C}$. The amount of GRN released was determined by analyzing the drug concentration in the filtered samples $(1 \mathrm{ml})$, withdrawn at predetermined time intervals. The samples were analyzed using a modified RP-HPLC at a wavelength of $305 \mathrm{~nm}$. The cumulative drug release (\%) was calculated and plotted against time.

\section{Ex Vivo Permeation Studies}

The ex vivo permeation studies were carried out using a Franz diffusion cell mounted with excised rat skin, with the stratum corneum facing the donor compartment. The drug-releasing surface of the transdermal film under evaluation was placed in contact with the stratum corneum side of the skin. The receiver compartment contained magnetically stirred PBS (18 ml, pH 7.4), maintained at $37 \pm 0.5^{\circ} \mathrm{C}$. The amount of $\mathrm{GRN}$ permeated was determined by analyzing the drug concentration in the filtered samples $(1 \mathrm{ml})$, withdrawn at predetermined time intervals. The samples were analyzed using a modified RP-HPLC at a wavelength of $305 \mathrm{~nm}$. The cumulative GRN permeated (\%) was calculated and plotted against time.

The target flux was calculated using the equation described previously by Suwanpidokkul et al. (Eq. (10)) (30):

$J_{\text {target }}=\frac{C_{\mathrm{SS}_{\mathrm{S}} \mathrm{Cl}_{\mathrm{t}} \mathrm{BW}}}{A}$

where $A$ represents the surface area of the transdermal film (i.e., $\left.2.5 \mathrm{~cm}^{2}\right)$; BW, the standard human body weight of $60 \mathrm{~kg}$; $C_{\mathrm{SS}}$, the GRN concentration at the therapeutic level (3.07 $\mu \mathrm{g} / \mathrm{l})$; and $\mathrm{Cl}_{\mathrm{t}}$, the total clearance $(0.52 \mathrm{l} / \mathrm{h})$. The calculated target flux value for GRN was $42.57 \mu \mathrm{g} / \mathrm{h} / \mathrm{cm}^{2}$.

\section{Statistical Analysis}

The statistical analysis was carried out by a two-way analysis of variance (ANOVA), followed by Bonferroni post-test using GraphPad $^{\circledR}$ Prism $^{\circledR}$ software version 5.03 (San Diego, CA). The results were expressed as mean \pm standard deviation (SD). The differences between the means were considered to be significant if the $P$ value was $<0.05$.

\section{RESULTS}

\section{Effect of Penetration Enhancers on the Permeation of Granisetron}

The influence of selected terpenes on the cumulative permeation of GRN through rat skin is shown in Fig. 2. The penetration-enhancing efficiency of these terpenes was found to be in the order D-limonene $(90 \%)>\alpha$-terpineol $(72 \%)>$ eugenol $(60 \%)>$ menthol $(48 \%)$. All tested terpenes demonstrated a significant $(P<0.05)$ improvement in the permeation of GRN across the rat skin compared with the control $(22 \%)$ at the end of $24 \mathrm{~h}$. These results are in agreement with those reported previously.

The calculated transdermal flux values of GRN obtained with D-limonene, $\alpha$-terpineol, eugenol, and menthol were found to be $33.37 \pm 2.16,26.70 \pm 0.84,22.25 \pm 1.58$, and $17.80 \pm$ $1.05 \mu \mathrm{g} / \mathrm{cm}^{2} / \mathrm{h}$, respectively. These values were found to be significantly $(P<0.05)$ higher compared with those of the 


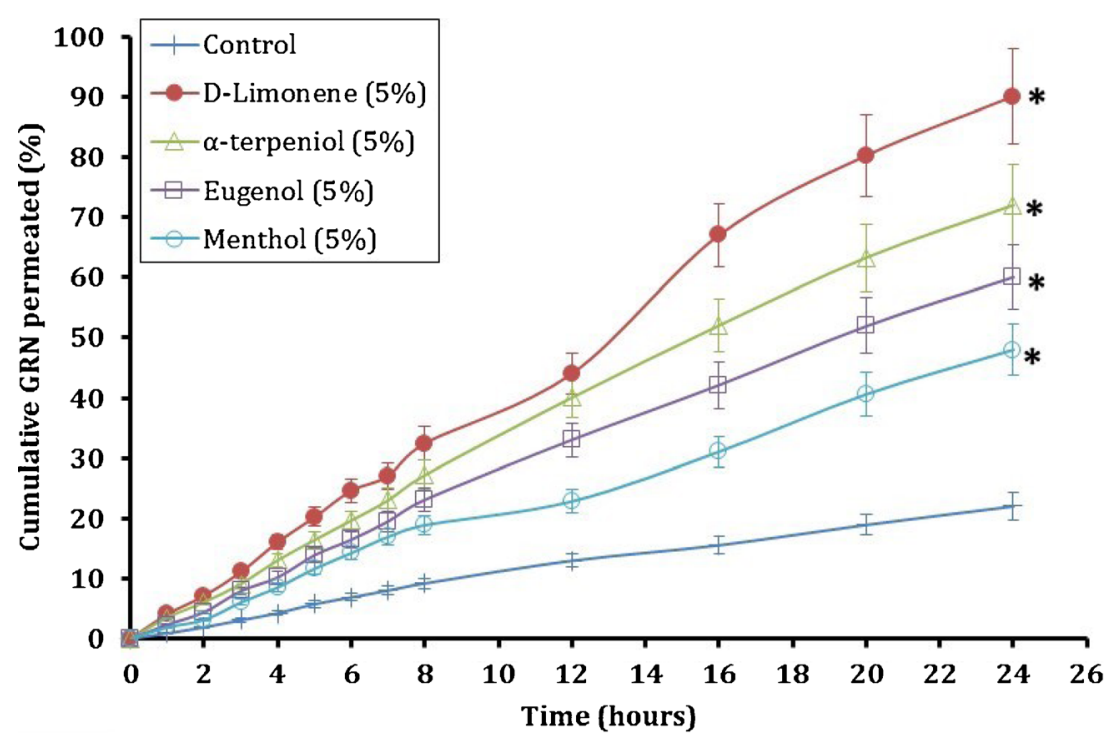

Fig. 2. Effect of penetration enhancers on the permeation of GRN. All values are mean \pm SD $(n=3) . * P<0.01$, compared to control

control $\left(8.16 \pm 0.62 \mu \mathrm{g} / \mathrm{cm}^{2} / \mathrm{h}\right)$. In addition, the calculated permeability coefficient values for D-limonene, $\alpha$-terpineol, eugenol, and menthol were found to be $4.08 \pm 0.27,3.27 \pm$ $0.21,2.73 \pm 0.16$, and $2.18 \pm 0.11 \mathrm{~cm} / \mathrm{h} \times 10^{-2}$, respectively.

\section{Drug-Polymer Compatibility Studies}

The DSC thermogram of pure GRN showed a sharp endothermic peak at $\sim 300^{\circ} \mathrm{C}$, corresponding to the GRN melting point (thermograms not shown). The appearance of a sharp endothermic peak is typically attributable to the crystalline nature of the materials. The DSC thermogram of Methocel $^{\circledR}$ E15, Eudragit ${ }^{\circledR}$ RL 100, and Eudragit ${ }^{\circledR}$ RS 100 revealed broad, undefined peaks over a temperature range of $60-240^{\circ} \mathrm{C}$. Such broad endothermic peaks, mainly due to the dehydration process, are typically observed with predominantly amorphous polymers.

The FTIR spectral analysis of pure GRN showed the main peaks at wave numbers $3246,1647,1557,1478$, and $1248 \mathrm{~cm}^{-1}$, confirming the purity of the drug (Fig. 3). The FTIR spectra of the ternary mixtures, GRN:Methocel ${ }^{\circledR}$ E15:Eudragit ${ }^{\circledR}$ RL $100(1: 1: 1)$ and GRN:Methocel ${ }^{\circledR}$ E15:Eudragit ${ }^{\circledR}$ RS 100 (1:1:1), showed that the major peaks of GRN were retained and observed at wave numbers 3245 , $1646,1561,1471$, and $1248 \mathrm{~cm}^{-1}$. The presence of the polymers did not appear to significantly affect the integrity of the GRN peaks.

\section{Physicochemical Properties of the Films}

The results of the physicochemical properties of the prepared transdermal matrix films are shown in Table II. The mean weights of the prepared films from all ten formulations ranged between 55 and $58 \mathrm{mg}$, and no significant differences were observed among the formulations evaluated. The changes in the ratio of the incorporated polymers in the formulation did not appear to have a statistically significant influence on the weight of the films. The thickness of the prepared films ranged between 92 and $107 \mu \mathrm{m}$. The film thickness appeared to decrease with decreasing ratio of the Methocel ${ }^{\circledR}$ E15:Eudragit ${ }^{\circledR}$ polymer in the formulations. These results are in agreement with those reported previously $(31,32)$. The results of the flatness study showed that the formulation films had a negligible change in the length along the longitudinally cut edges, indicating a near $100 \%$ flatness. The films from all tested formulations appeared to have a smooth, flat surface, without any visible signs of constriction.

The results of the content uniformity assay of the prepared films are shown in Table II. The GRN content of the films from different formulations, as obtained from the HPLC assay, ranged from 98 to $100 \% \mathrm{w} / \mathrm{w}$ of the theoretical concentration. The drug content was found to be statistically similar across different formulations. The results indicated that the process employed to prepare films in this study was robust and capable of producing films without a significant variation. The folding endurance test results (Table II) showed that the films prepared from all formulations endured at least 250 strokes of folding/unfolding at the same location before revealing any signs of cracking/breaking. These results were found to be higher than those reported in the literature for similar formulations (17). These results demonstrated the sturdiness of the films in maintaining their integrity with general skin folding when applied.

The moisture content of the prepared films from all the formulations at ambient conditions ranged between 2 and $7 \%$ $w / w$. The composition of Methocel ${ }^{\circledR}$ E15 in the formulations was found to influence the moisture content of the films (Fig. 4a, b). The moisture content increased in a linear manner with increasing levels of Methocel ${ }^{\circledR}$ E15 for formulations containing Eudragit ${ }^{\circledR}$ RL $100\left(R^{2}=0.9787\right)$ or Eudragit ${ }^{\circledR}$ RS $100\left(R^{2}=0.9807\right)$. The moisture content among the formulations containing similar concentrations of either Eudragit $^{\circledR}$ RL 100 or Eudragit ${ }^{\circledR}$ RS 100 was not found to be significantly different.

The results of the moisture uptake by the prepared films at elevated conditions of humidity, i.e., $60 \% \mathrm{RH}, 75 \% \mathrm{RH}$, and $90 \%$ RH, are shown in Fig. 5a, b. Similar to the moisture content results, the moisture uptake by the prepared 
a

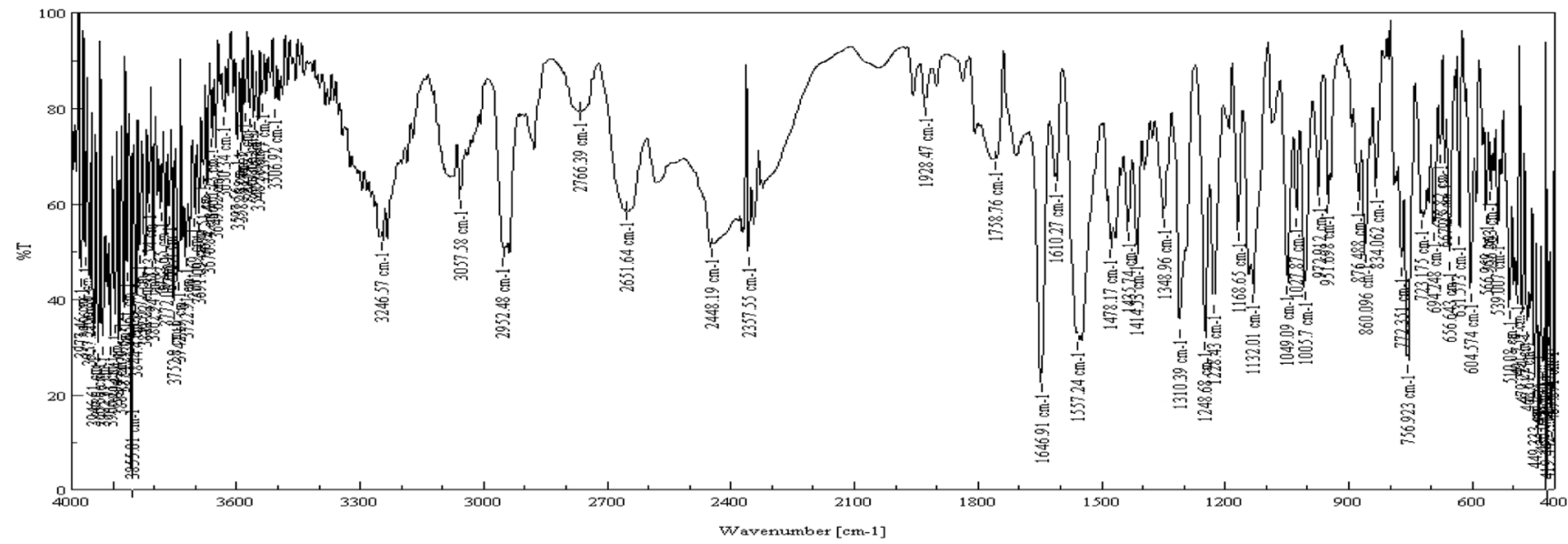

b

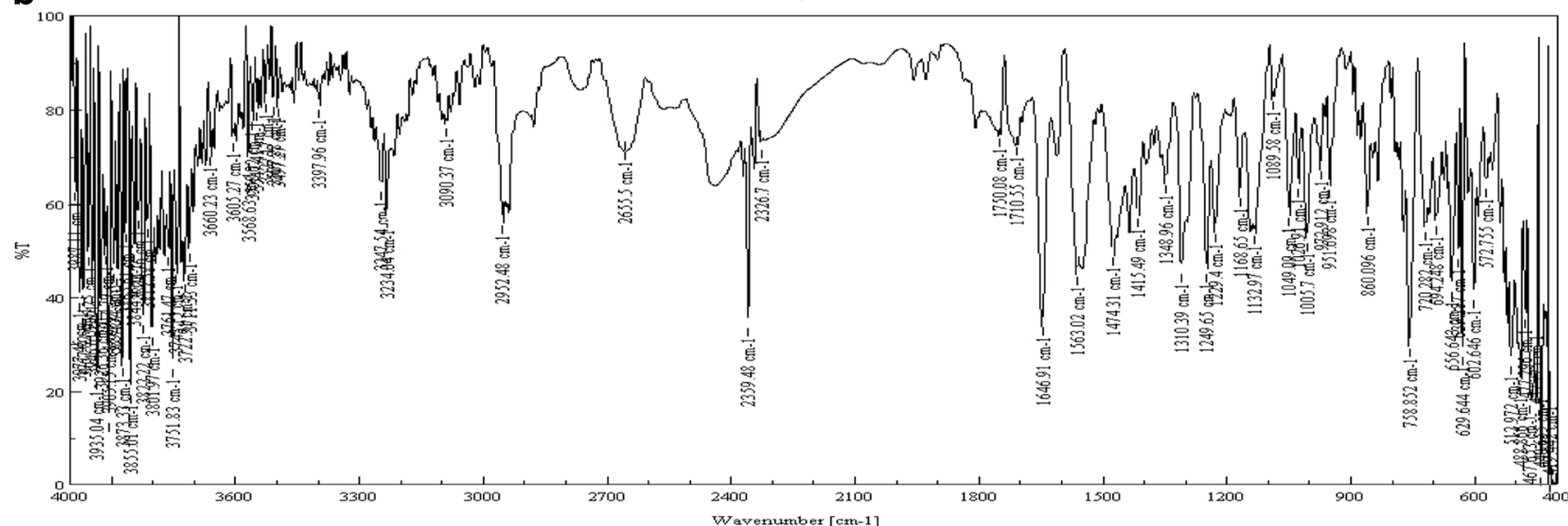

C

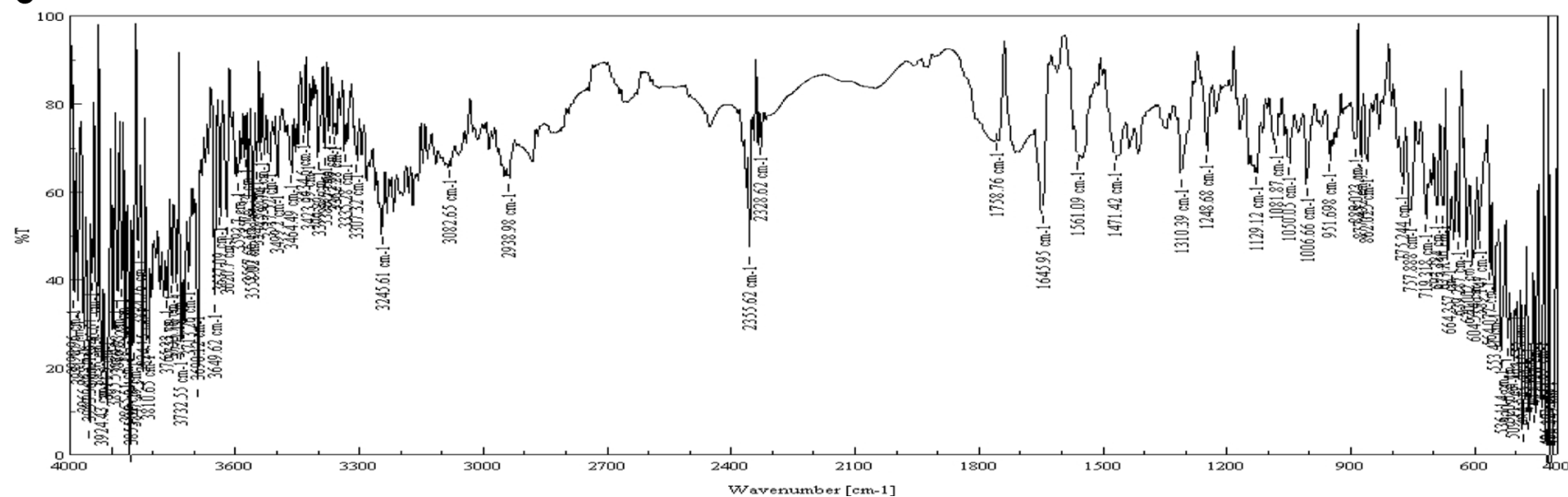

Fig. 3. FTIR analysis of the drug and the polymers. a Granisetron, b granisetron:Methocel ${ }^{\circledR}$ E15:Eudragit ${ }^{\circledR}$ RL 100 (1:1:1), and $\mathbf{c}$ granisetron:Methocel ${ }^{\circledR}$ E15:Eudragit ${ }^{\circledR}$ RS 100 (1:1:1)

formulation films appeared to depend on the amount of Methocel ${ }^{\circledR}$ E15 in the formulations. For the formulations containing Eudragit ${ }^{\circledR}$ RL 100 (Fig. 5a), the moisture uptake increased linearly with increasing Methocel ${ }^{\circledR} \mathrm{E} 15$ at $60 \% \mathrm{RH}$ $\left(R^{2}=0.9568\right), 75 \% \mathrm{RH}\left(R^{2}=0.9989\right)$, and $90 \% \mathrm{RH}\left(R^{2}=\right.$ 0.9982). Similarly, for the formulations containing Eudragit ${ }^{\circledR}$ RS 100 (Fig. 5b), the moisture uptake increased linearly with increasing Methocel ${ }^{\circledR}$ E15 at $60 \%$ RH $\left(R^{2}=0.9485\right), 75 \%$ RH
$\left(R^{2}=0.992\right)$, and $90 \% \mathrm{RH}\left(R^{2}=0.9992\right)$. As observed with moisture content results, the moisture uptake among the formulations containing similar concentrations of either Eudragit $^{\circledR}$ RL 100 or Eudragit ${ }^{\circledR}$ RS 100 was not found to be significantly different.

The water vapor transmission rates (WVTR) in the prepared films were found to range between 0.09 and $0.56 \mathrm{mg} /$ $\mathrm{cm}^{2} / \mathrm{h}$. These results were in agreement with those reported 
Table II. Physicochemical Properties of GRN Films

\begin{tabular}{|c|c|c|c|c|c|c|c|}
\hline Formulation & Weight (mg) & Thickness $(\mu \mathrm{m})$ & $\begin{array}{l}\text { Tensile strength } \\
\left(\mathrm{kg} / \mathrm{mm}^{2}\right)\end{array}$ & Elongation (\%) & $\begin{array}{l}\text { Folding } \\
\text { endurance } \\
\text { (no. of strokes) }\end{array}$ & Drug content (\%) & Flatness \\
\hline $\mathrm{F} 1$ & $56.21(4.92)$ & $107(3.02)$ & $11.01(0.59)$ & $62.50(1.09)$ & $257.12(3.68)$ & $99.47(0.26)$ & $100.08(0.12)$ \\
\hline $\mathrm{F} 2$ & 55.18 (5.09) & $104(2.54)$ & $10.43(0.47)$ & $60.09(1.95)$ & $263.47(4.98)$ & $99.87(0.35)$ & $100.14(0.09)$ \\
\hline F3 & $58.03(3.12)$ & $99(2.19)$ & $11.73(0.82)$ & $61.82(1.30)$ & $252.41(3.64)$ & $99.42(0.50)$ & $99.98(0.17)$ \\
\hline F4 & $56.47(3.69)$ & $95(2.71)$ & $9.57(0.62)$ & $59.07(2.00)$ & $255.28(4.10)$ & $98.89(0.31)$ & $100.02(0.16)$ \\
\hline F5 & $56.08(4.79)$ & $92(2.59)$ & $10.68(0.66)$ & $64.13(1.83)$ & $254.09(3.83)$ & $100.23(0.54)$ & $100.16(0.13)$ \\
\hline F6 & $57.41(3.28)$ & $106(3.18)$ & $10.64(0.78)$ & $62.24(1.30)$ & $259.28(4.10)$ & $99.32(0.52)$ & $99.95(0.11)$ \\
\hline F7 & $55.20(4.64)$ & $104(2.55)$ & $10.85(0.92)$ & $61.85(1.88)$ & $253.27(4.80)$ & $99.73(0.46)$ & $100.04(0.16)$ \\
\hline F8 & $57.18(3.19)$ & $98(2.41)$ & $11.81(0.68)$ & $63.04(1.70)$ & 253.14 (3.99) & $99.05(0.53)$ & $100.11(0.15)$ \\
\hline F9 & $58.14(3.20)$ & $96(2.67)$ & $10.22(0.49)$ & $63.54(1.05)$ & $251.27(4.53)$ & $98.94(0.57)$ & $99.93(0.10)$ \\
\hline F10 & $57.16(3.33)$ & $93(2.04)$ & $10.69(0.78)$ & $63.26(1.83)$ & $251.40(3.87)$ & $98.91(0.47)$ & $100.02(0.15)$ \\
\hline
\end{tabular}

All values are expressed as mean (standard deviation), $n=3$

previously $(21,33)$. Similar to the results obtained from the moisture content and moisture uptake studies, the WVTR of the prepared films appeared to correlate linearly with Methocel ${ }^{\circledR}$ E15 levels in the formulations. For the formulations containing Eudragit ${ }^{\circledR}$ RL 100 (Fig. 6a), the WVTR increased linearly with increasing Methocel ${ }^{\circledR}$ E15 at $60 \% \mathrm{RH}\left(R^{2}=0.8542\right), 75 \% \mathrm{RH}\left(R^{2}=0.9991\right)$, and $90 \% \mathrm{RH}$ $\left(R^{2}=0.9822\right)$. Similarly, for the formulations containing Eudragit $^{\circledR}$ RS 100 (Fig. 6b), the moisture uptake increased linearly with increasing Methoce ${ }^{\circledR} \mathrm{E} 15$ at $60 \% \mathrm{RH}\left(R^{2}=\right.$ $0.9454), 75 \% \mathrm{RH}\left(R^{2}=0.9914\right)$, and $90 \% \mathrm{RH}\left(R^{2}=0.9904\right)$.
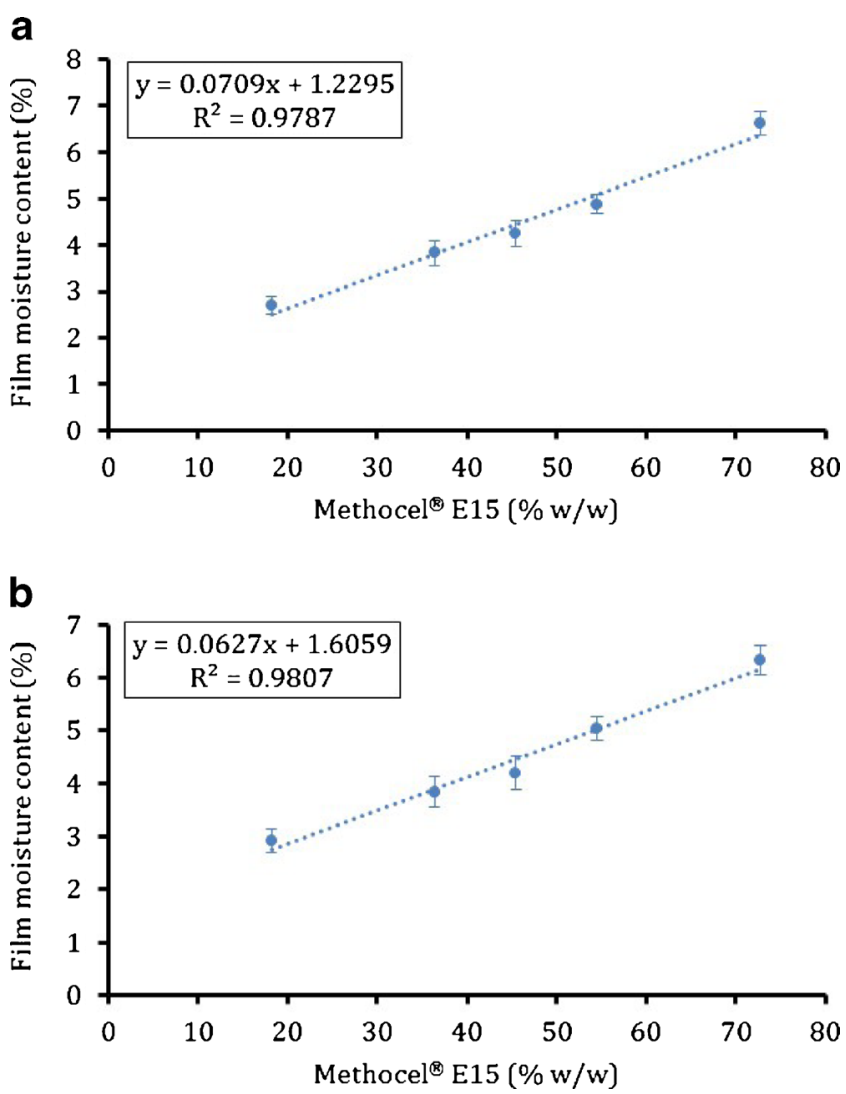

Fig. 4. The effect of Methocel ${ }^{\circledR}$ E15 levels on the moisture content (\%) of the prepared films. a Formulations containing Eudragit ${ }^{\circledR} \mathrm{RL}$ 100. b Formulations containing Eudragit ${ }^{\circledR}$ RS 100

\section{In Vitro Drug Release}

The results of the in vitro drug release from transdermal films are shown in Fig. 7a, b and Table III. Figure 7a shows the influence of the ratio of Methocel ${ }^{\circledR}$ E15 and Eudragit ${ }^{\circledR}$ RL 100 on the release of GRN from the prepared transdermal films. It was observed that the formulation $\mathrm{F} 1$ (with the highest ratio of Methocel $^{\circledR}$ E15:Eudragit ${ }^{\circledR}$ RL 100) exhibited the highest cumulative amount of GRN released (Table III). For the subsequent formulations, i.e., F2 to F5, the release of GRN was found to be progressively slower. Similar results were
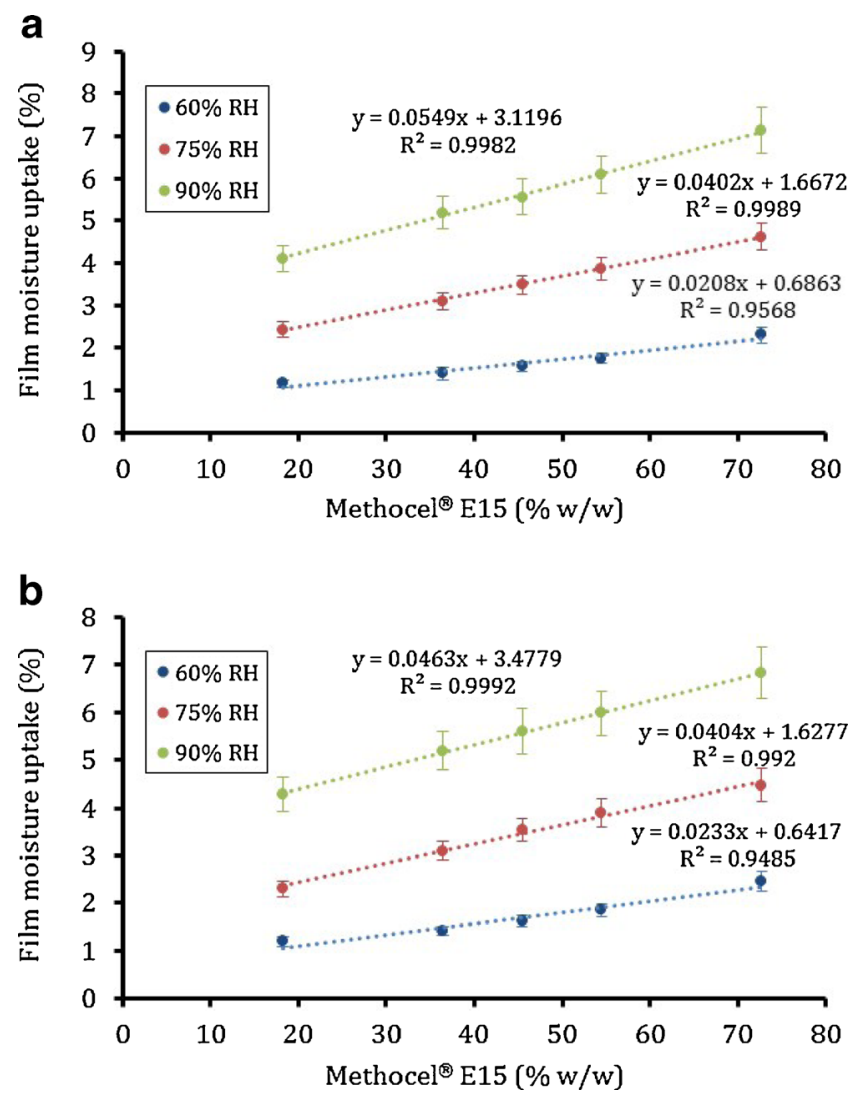

Fig. 5. The effect of Methocel ${ }^{\circledR}$ E15 levels on the moisture uptake (\%) of the prepared films. a Formulations containing Eudragit ${ }^{\circledR} \mathrm{RL}$ 100. b Formulations containing Eudragit ${ }^{\circledR}$ RS 100 

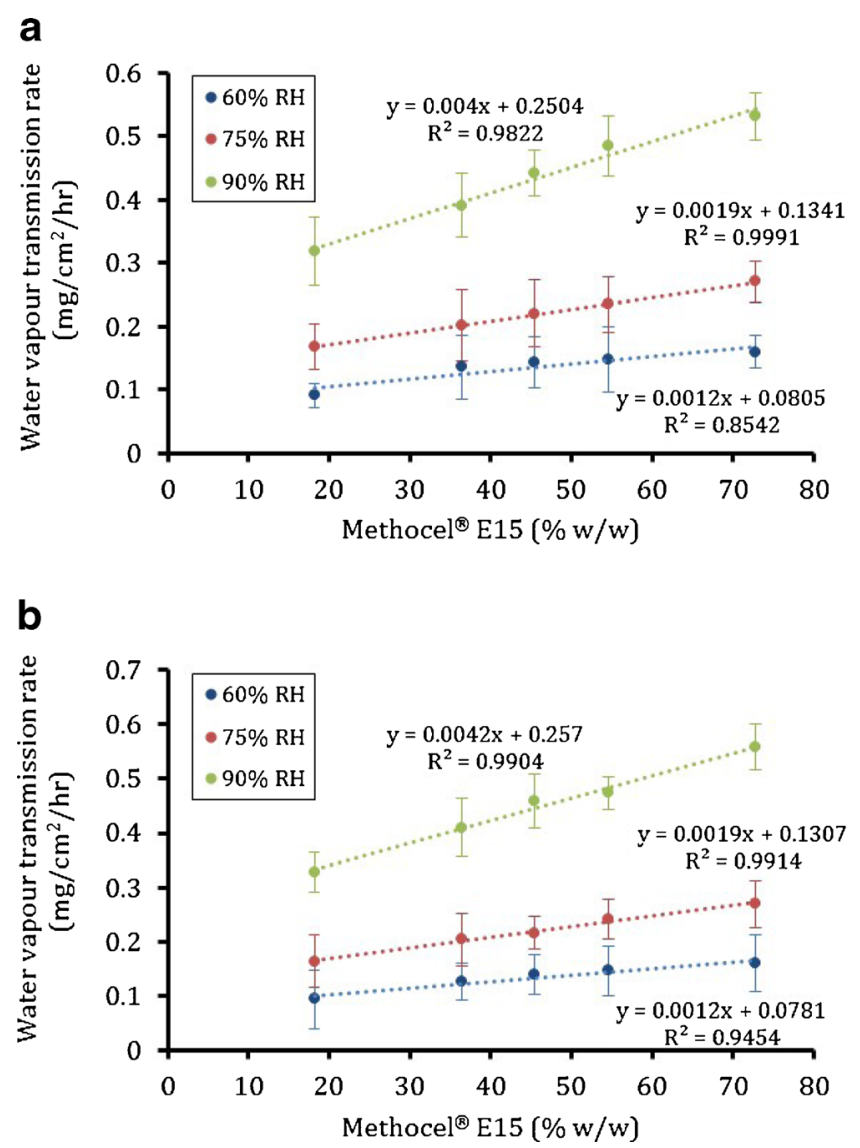

Fig. 6. The effect of Methocel ${ }^{\circledR}$ E15 levels on the water vapor transmission rate of the films. a Formulations containing Eudragit ${ }^{\circledR}$ RL 100. b Formulations containing Eudragit ${ }^{\circledR}$ RS 100

observed with formulations containing Eudragit ${ }^{\circledR}$ RS 100 (Fig. 7b). The formulation F6 (with the highest ratio of Methocel $^{\circledR}$ E15:Eudragit ${ }^{\circledR}$ RS 100) exhibited the highest cumulative amount of GRN released, and for the subsequent formulations, i.e., F7 to F10, the release of GRN was found be progressively slower. Thus, compared with the control, the GRN release appeared to be significantly influenced by the ratio of Methocel ${ }^{\circledR}$ E15 and Eudragit ${ }^{\circledR}$ polymers. The enhancement of drug release in the presence of a hydrophilic component to an insoluble film former has been reported earlier (34).

\section{Ex Vivo Drug Permeation}

The results of the ex vivo drug permeation studies (across the excised rat skin) from transdermal films are shown in Fig. 8a, b and Table III. Similar to the results obtained from the in vitro drug release studies, it was observed that the formulation F1 (with the highest ratio of Methocel ${ }^{\circledR}$ E15:Eudragit ${ }^{\circledR}$ RL 100) exhibited the highest cumulative amount of GRN permeated (Table III). For the subsequent formulations, i.e., $\mathrm{F} 2$ to $\mathrm{F} 5$, the permeation of GRN was found to be progressively slower (Fig. 8a). Similar results were observed with formulations containing Eudragit ${ }^{\circledR}$ RS 100 (Fig. 8b). The formulation F6 (with the highest ratio of Methocel $^{\circledR}$ E15:Eudragit ${ }^{\circledR}$ RS 100) exhibited the highest a

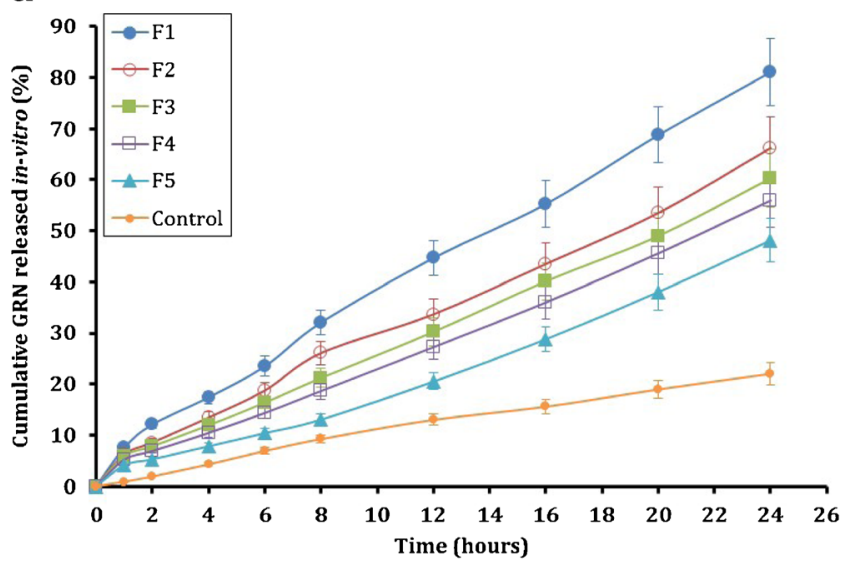

b

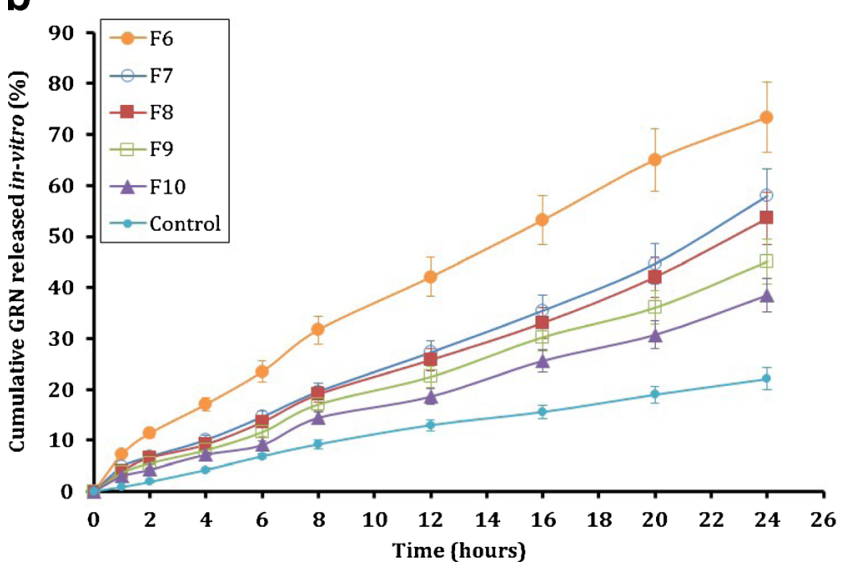

Fig. 7. The in vitro release of GRN from transdermal films. a Formulations containing Eudragit ${ }^{\circledR}$ RL 100. b Formulations containing Eudragit $^{\circledR}$ RS $100(n=3)$

cumulative amount of GRN permeated, and for the subsequent formulations, i.e., F7 to F10, the permeation of GRN was found be progressively slower. Thus, GRN permeation through the rat skin also appeared to be influenced by the ratio of Methocel ${ }^{\circledR}$ E15 and Eudragit ${ }^{\circledR}$ polymers.

\section{Transdermal Flux, Permeation Coefficient, and Enhancement Ratio}

The results of the calculated steady-state transdermal flux values $\left(J_{\mathrm{ss}}\right)$ are shown in Fig. 9a, b and Table III. The $J_{\mathrm{ss}}$ values were found to increase in a linear manner with increasing levels of Methocel ${ }^{\circledR}$ E15 in the formulations containing Eudragit $^{\circledR}$ RL $100\left(R^{2}=0.9868\right)$ (Fig. 9a) or Eudragit ${ }^{\circledR}$ RS $100\left(R^{2}=0.9915\right)\left(\right.$ Fig. 9b). The $J_{\mathrm{ss}}$ values among the formulations containing similar concentrations of either Eudragit $^{\circledR}$ RL 100 or Eudragit ${ }^{\circledR}$ RS 100 were not found to be significantly different.

Similar trends were observed in the calculated permeability coefficient and the enhancement ratio results for the formulations (Fig. 10a, b and Table III). For the formulations containing Eudragit ${ }^{\circledR}$ RL 100, the permeability coefficient $\left(R^{2}=0.9229\right)$ and the enhancement ratio $\left(R^{2}=0.9864\right)$ values 
Table III. The In Vitro Drug Release, Ex Vivo Skin Permeation, Transdermal Flux, Permeability Coefficient, and Enhancement Ratio of GRN Films

\begin{tabular}{llllll}
\hline Formulation & $Q_{24}\left(\mu \mathrm{g} / \mathrm{cm}^{2}\right)^{a}$ & $Q_{24}\left(\mu \mathrm{g} / \mathrm{cm}^{2}\right)^{b}$ & Transdermal flux $\left(J_{\mathrm{ss}}\right)$ & Permeability coefficient $\left(K_{\mathrm{p}}{ }^{d}\right)$ & Enhancement ratio $($ ER $)$ \\
\hline F1 & $1297.28(103.2)$ & $1200.16(115.6)$ & $42.05(3.71)$ & $1.20(0.09)$ & $1.62(0.13)$ \\
F2 & $1060.32(97.7)$ & $1025.44(99.2)$ & $38.83(3.52)$ & $1.10(0.08)$ & $1.59(0.10)$ \\
F3 & $964.96(89.9)$ & $950.72(93.2)$ & $35.19(3.28)$ & $1.00(0.09)$ & $1.45(0.09)$ \\
F4 & $895.20(82.7)$ & $802.08(85.6)$ & $32.65(2.51)$ & $0.93(0.08)$ & $1.42(0.09)$ \\
F5 & $770.24(68.6)$ & $688.96(63.3)$ & $27.87(2.25)$ & $0.79(0.07)$ & $1.32(0.09)$ \\
F6 & $1174.72(111.5)$ & $1053.44(99.2)$ & $40.35(3.49)$ & $1.15(0.09)$ & $1.54(0.12)$ \\
F7 & $927.36(83.6)$ & $881.44(82.2)$ & $35.77(3.29)$ & $1.02(0.08)$ & $1.52(0.13)$ \\
F8 & $856.64(81.2)$ & $793.12(72.9)$ & $32.90(2.72)$ & $0.94(0.07)$ & $1.45(0.10)$ \\
F9 & $721.44(68.6)$ & $643.36(56.8)$ & $30.69(2.58)$ & $0.87(0.08)$ & $1.39(0.10)$ \\
F10 & $615.84(53.4)$ & $557.92(51.0)$ & $23.95(2.11)$ & $0.68(0.05)$ & $1.26(0.107)$ \\
\hline
\end{tabular}

All values are expressed as mean (SD), $n=3$

${ }^{a}$ Cumulative amount of drug released at the end of $24 \mathrm{~h}$

${ }^{b}$ Cumulative amount of drug permeated at the end of $24 \mathrm{~h}$

appeared to vary linearly as a function of Methocel ${ }^{\circledR}$ E15 composition.

Similarly, for the formulations containing Eudragit ${ }^{\circledR} \mathrm{RL}$ 100 , increasing levels of Methocel ${ }^{\circledR}$ E15 resulted in a linear increase in the permeability coefficient $\left(R^{2}=0.9139\right)$ and the enhancement ratio $\left(R^{2}=0.9915\right)$ values.

a

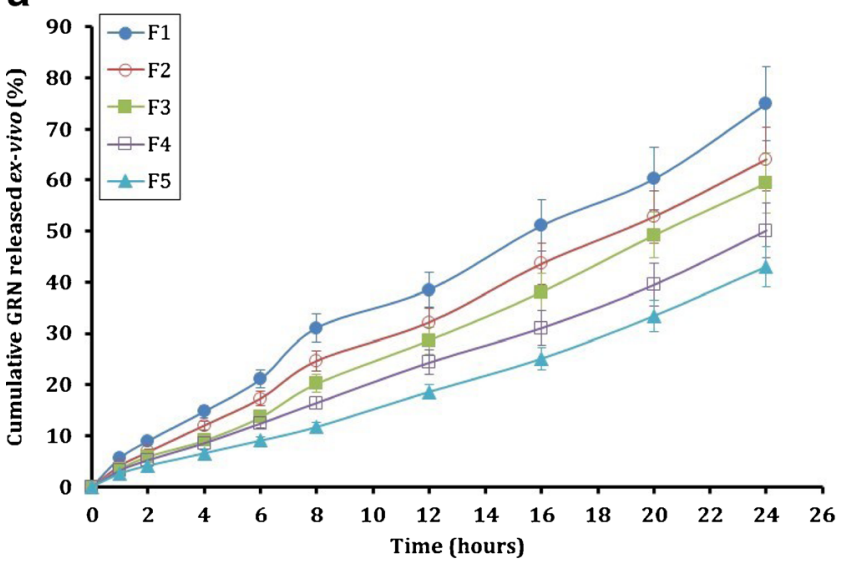

b

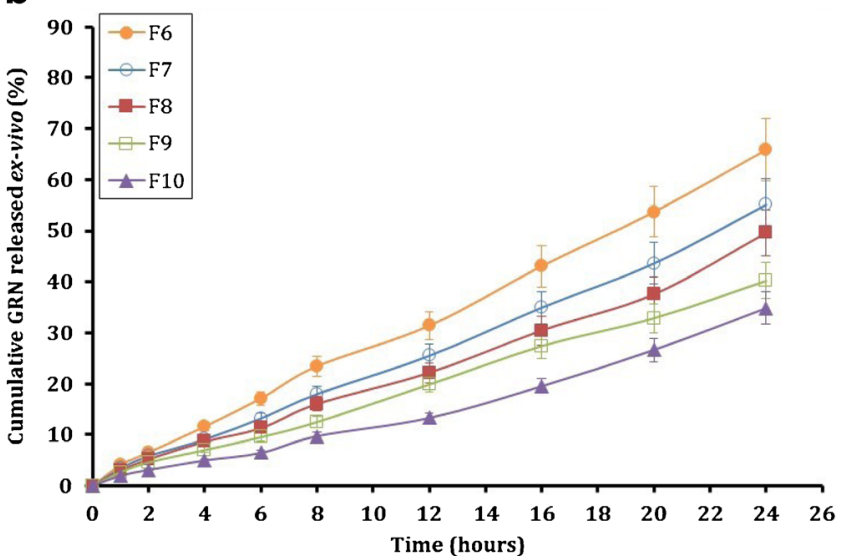

Fig. 8. The ex vivo permeation of GRN from transdermal films. a Formulations containing Eudragit ${ }^{\circledR}$ RL 100. b Formulations containing Eudragit ${ }^{\circledR}$ RS $100(n=3)$

\section{DISCUSSION}

Terpenes are known to function as permeation enhancers when incorporated in transdermal formulations (35). In the current study, the comparative permeation-enhancing efficiency of four terpenes, i.e., D-limonene, $\alpha$-terpineol, eugenol, and menthol, was evaluated. The hydrocarbon- or non-polargroup-containing terpenes such as limonene typically provide a better penetration-enhancing effect for the lipophilic drugs,
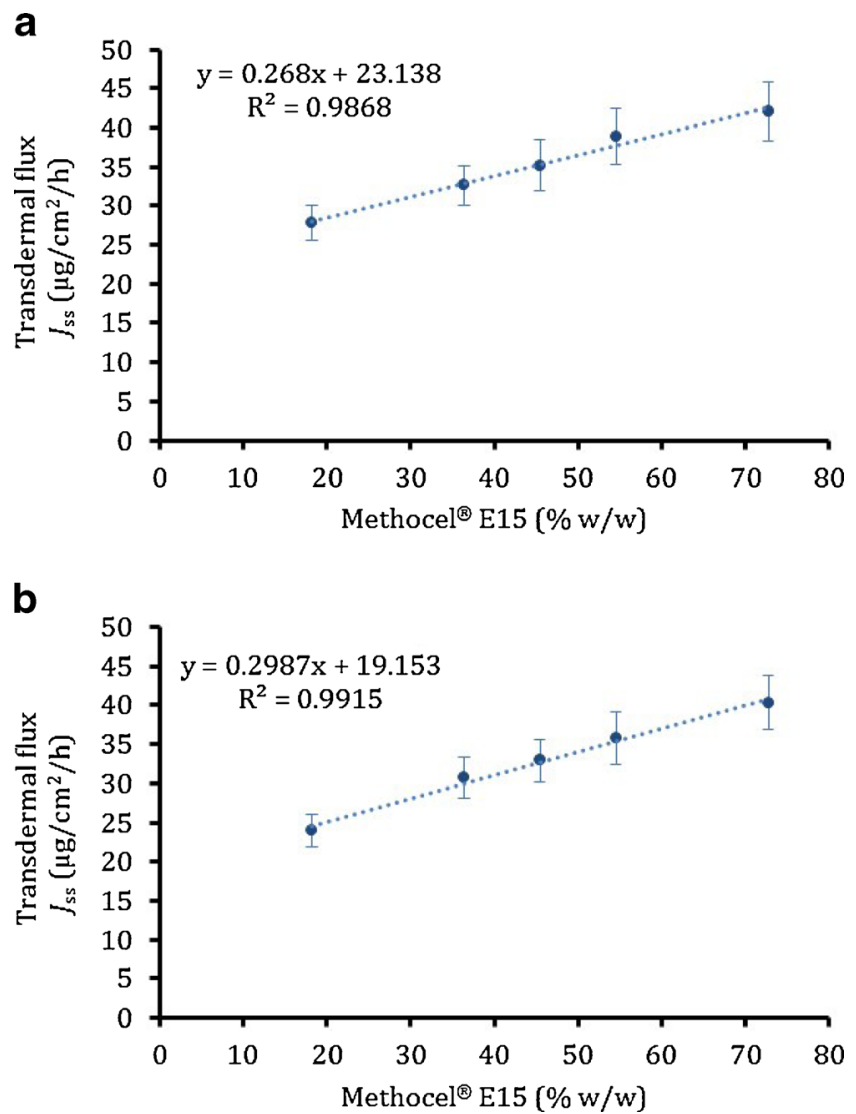

Fig. 9. Transdermal flux of GRN from the film formulations. a Formulations containing Eudragit ${ }^{\circledR}$ RL 100. b Formulations containing Eudragit $^{\circledR}$ RS 100 

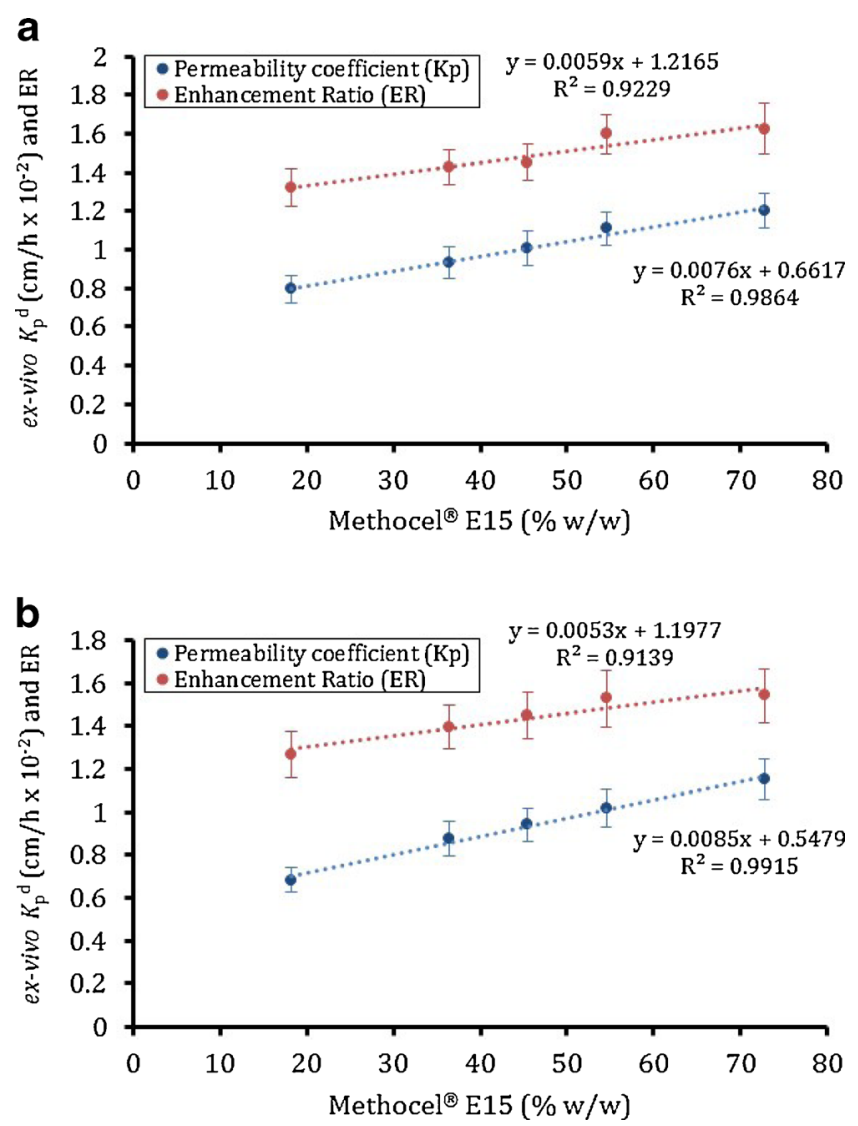

Fig. 10. Permeability coefficient and enhancement ratio of GRN from transdermal films. Values are mean $\pm \mathrm{SD}(n=3)$

compared with the polar terpenes. D-Limonene is previously reported to be effective in enhancing the transport of lipophilic molecules such as indomethacin, midazolam, and estradiol (36). D-Limonene is a hydrophobic terpene, lacking a hydroxyl group ( $\log \mathrm{P} 4.58 \pm 0.23)$, and the mechanism of its permeation-enhancing effects is thought to be due to an increase in the partitioning of the drug molecules into the lipid bilayer of the stratum corneum (37). Based on the results obtained from the GRN permeation, the calculated transdermal flux, and the permeation coefficient values, D-limonene was identified as the best permeation enhancer among the terpenes evaluated. D-Limonene was thus selected to be incorporated into the formulations prepared to further investigate the influence of other formulation variables on the functionality of the transdermal films.

The DSC analysis of the ternary mixtures, GRN:Methocel ${ }^{\circledR}$ E15:Eudragit ${ }^{\circledR}$ RL 100 (1:1:1) and GRN:Methocel ${ }^{\circledR}$ E15:Eudragit ${ }^{\circledR}$ RS 100 (1:1:1), revealed a negligible and a non-significant change in the melting point of GRN $\left(\sim 300^{\circ} \mathrm{C}\right)$ in the presence of these polymers.

Additionally, the melting signal (endotherm) was clearly distinguishable in both ternary mixtures. Since no other endothermic/exothermic event was observed in this region, any interaction or obvious incompatibility between the drug and the polymers can be safely excluded. The DSC results thus indicated the suitability of these polymers to be used in the transdermal film formulations (19). Similarly, the FTIR analysis of the ternary mixtures of the drug and the polymers did not reveal any interferences with the major peaks associated with GRN. The DSC and FTIR results thus indicated that the drug and polymers are compatible. Methocel ${ }^{\circledR}$ E15, Eudragit ${ }^{\circledR}$ RL 100, and Eudragit ${ }^{\circledR}$ RS 100 are commonly used polymers, incorporated in a wide range of controlled/ sustained-release matrix-type transdermal drug delivery systems due to their compatibility with several drugs (38).

The prepared transdermal films were evaluated for the physicochemical properties using commonly used, wellestablished, and standard methods. The physical characteristics of the films such as weight variation, thickness, and flatness were found to be consistent among the formulations and within acceptable limits. The moisture content and the moisture uptake values of the prepared films were found to be dependent on the incorporated hydrophilic polymer ratio. An increase in the moisture content and moisture uptake by polymeric films as a function of increasing levels of hydrophilic polymers has been reported earlier $(18,31,32,39)$. A small amount of moisture in the films is thought to be essential to maintain the stability and integrity of the films and to prevent excessive drying (resulting in brittleness and cracking) of the films $(18,39)$. The water vapor transmission rate (WVTR) is a parameter commonly used to evaluate the amount of moisture transmitted through the transdermal films containing hydrophilic polymers $(21,40)$. The prepared transdermal films showed predictable and linearly proportional WVTR values with increasing Methocel ${ }^{\circledR}$ E15 content. Tanwar et al. have previously reported higher film WVTR values for HPMCbased films and attributed this to the hydrophilicity of the polymer incorporated (33).

The physicochemical properties of the drug and the delivery system, as well as the physiological and physicochemical properties of the biological membrane, typically determine the rate and extent of the drug release from the transdermal films (41). In an attempt to describe the release kinetics of GRN from the prepared transdermal films, the results from the in vitro release studies was fitted to different kinetic models such as the zero-order release, first-order release, Higuchi, and Korsmeyer-Peppas release models (42). The cumulative amount of drug released from the films, when plotted against the square root of time, exhibited release profiles of the drug which appeared to follow the Higuchi model, as evidenced by the range of correlation coefficient values $\left(R^{2}=0.97\right.$ to 0.99$)$. The correlation coefficient values for the zero-order $\left(R^{2}=0.93\right.$ to 0.95$)$ and the first-order $\left(R^{2}=0.56\right.$ to 0.60$)$ kinetics were lower than those for the Higuchi kinetics (Table IV). Korsmeyer et al. used a simple empirical equation (Eq. (11)) to describe the release behavior of molecules from the polymer matrices (16):

$\frac{M_{t}}{M_{\infty}}=K t_{n}$

where $\frac{M_{t}}{M_{\infty}}$ is the fraction of drug released, $K$ is the rate constant, $t$ is time for the drug release, and $n$ is the diffusional exponent for drug release. Peppas stated that, regardless of the mechanism of release, the above equation can describe the drug release from polymer matrices of various geometries. The release mechanism is typically indicated by the value of the diffusional exponent $(n)$. For example, when $n=1$, the release can be considered "zero-order" (case II transport), 
Table IV. In Vitro Release Kinetics of GRN Films

\begin{tabular}{lllll}
\hline & $\begin{array}{l}\text { Zero } \\
\text { order } \\
\left(R^{2}\right)\end{array}$ & $\begin{array}{l}\text { First } \\
\text { order } \\
\left(R^{2}\right)\end{array}$ & $\begin{array}{l}\text { Higuchi } \\
\text { model } \\
\left(R^{2}\right)\end{array}$ & $\begin{array}{l}\text { Korsmeyer-Peppas } \\
\text { model }(n)\end{array}$ \\
\hline F1 & 0.9312 & 0.6047 & 0.9907 & 0.5360 \\
F2 & 0.9456 & 0.6066 & 0.9824 & 0.5428 \\
F3 & 0.9404 & 0.5719 & 0.9724 & 0.6206 \\
F4 & 0.9376 & 0.5937 & 0.9849 & 0.6029 \\
F5 & 0.9564 & 0.5738 & 0.9857 & 0.6619 \\
F6 & 0.9439 & 0.5904 & 0.9749 & 0.5968 \\
F7 & 0.9579 & 0.5637 & 0.9726 & 0.6315 \\
F8 & 0.9438 & 0.5793 & 0.9852 & 0.5726 \\
F9 & 0.9379 & 0.5632 & 0.9705 & 0.7104 \\
F10 & 0.9468 & 0.5937 & 0.9747 & 0.7572 \\
\hline
\end{tabular}

and $n=0.5$ indicates a Fickian diffusion-based release; when $0.5<n<1.0$, diffusion and non-Fickian transport may be involved. Lastly, when $n>1.0$, the apparent mechanism is "super case II transport." The value of $n$ is obtained from the slope of $\log \frac{M_{t}}{M_{\infty}} v s$ the log time curve. The $n$ values for the GRN release obtained using this equation ( 0.53 to 0.75$)$ indicated that the main mechanism of GRN release from the prepared films was general, non-Fickian diffusion. The hydration and subsequent swelling of the incorporated hydrophilic polymer Methocel ${ }^{\circledR}$ E15 may possibly explain the observed mechanism of GRN release.

Overall, the formulations containing Eudragit ${ }^{\circledR}$ RL 100 exhibited GRN release that was higher in rate and extent, compared with those containing Eudragit ${ }^{\circledR}$ RS 100. Eudragit $^{\circledR}$ RL 100 contains a higher proportion of the hydrophilic quaternary ammonium groups compared with Eudragit ${ }^{\circledR}$ RS 100 , which may result in a rapid hydration of the matrix and subsequent drug release (33). An increase in the amount and hydrophobicity of the incorporated polymers is known to slow the drug release rates. In such cases, the mechanism of the drug release shifts towards polymer relaxation and matrix erosion $(43,44)$.

A mild burst release of GRN was observed with all formulations. This may be attributed to the direct exposure of the matrix films to dissolution media. Due to the hydrophilic nature of the polymer used, the polymeric matrix may form loose channels within the network, resulting in a rapid release of the drug present in the surface layers of the film. The

Table V. Ex Vivo Permeation Kinetics of GRN Films

\begin{tabular}{lllll}
\hline & $\begin{array}{l}\text { Zero } \\
\text { order } \\
\left(R^{2}\right)\end{array}$ & $\begin{array}{l}\text { First } \\
\text { order } \\
\left(R^{2}\right)\end{array}$ & $\begin{array}{l}\text { Higuchi } \\
\text { model } \\
\left(R^{2}\right)\end{array}$ & $\begin{array}{l}\text { Korsmeyer- } \\
\text { Peppas model } \\
(n)\end{array}$ \\
\hline F1 & 0.9679 & 0.6108 & 0.9907 & 0.5200 \\
F2 & 0.9745 & 0.6087 & 0.9921 & 0.5790 \\
F3 & 0.9684 & 0.6147 & 0.9903 & 0.5919 \\
F4 & 0.9803 & 0.6124 & 0.9865 & 0.5606 \\
F5 & 0.9748 & 0.6185 & 0.9912 & 0.6185 \\
F6 & 0.9684 & 0.6073 & 0.9906 & 0.5321 \\
F7 & 0.9843 & 0.6073 & 0.9858 & 0.6097 \\
F8 & 0.9642 & 0.6138 & 0.9931 & 0.6034 \\
F9 & 0.9753 & 0.6218 & 0.9914 & 0.6113 \\
F10 & 0.9734 & 0.6135 & 0.9925 & 0.7301 \\
\hline
\end{tabular}

observed initial release may assist in achieving the therapeutic plasma concentration of the drug in a short time, followed by a constant release over a longer period of time $(43,44)$. The initial burst release was observed to be higher in the matrix film Eudragit ${ }^{\circledR}$ RL 100 polymer compared with Eudragit ${ }^{\circledR}$ RS 100 , although this effect was not significant.

The cumulative amount of drug permeated (per square centimeter of films) through the rat abdominal skin, when plotted against time, exhibited permeation profiles that appeared to follow Higuchi's equation as evidenced by the calculated range of correlation coefficient values $\left(R^{2}=0.98\right.$ to $0.99)$. The correlation coefficient values for the first-order $\left(R^{2}=0.60\right.$ to 0.62$)$ and the zero-order $\left(R^{2}=0.96\right.$ to 0.98$)$ kinetics were found to be relatively lower than those obtained with the Higuchi kinetics (Table V). As described earlier by Rao et al., the initial rapid dissolution of the hydrophilic polymer occurs when the film is in contact with the hydrated skin, resulting in the accumulation of high amounts of drug in the skin surface, thus leading to saturation of the skin with drug molecules (45).

The calculated values of transdermal flux, permeation coefficient, and the enhancement ratio for the prepared films were found to increase linearly with increasing levels of the hydrophilic polymer, i.e., Methocel ${ }^{\circledR}$ E15 in the formulation. These parameters are commonly used to evaluate the functionality of transdermal preparations and to provide a better understanding of the mechanisms of transdermal absorption of drugs $(12,23)$. Hydrophilic-matrix-based films in the presence of permeation enhancers are known to demonstrate higher values of transdermal flux, permeation coefficient, and enhancement ratio.

\section{CONCLUSIONS}

The influence of formulation variables such as permeation enhancers (terpenes), hydrophilic matrix former (Methocel ${ }^{\circledR}$ E15), and film formers (Eudragit ${ }^{\circledR}$ RL 100 and Eudragit ${ }^{\circledR}$ RS 100) on the quality and functionality of a transdermal film formulation was evaluated. Consistent with the previous findings, D-limonene was found to be the most efficient permeation enhancer among the tested terpenes. The composition ratio of the hydrophilic matrix former and the film-forming polymers influenced the physicochemical and functional characteristics of the prepared films. A transdermal film formulation, having the required quality and performance attributes, can be optimally designed by the use of an appropriate type and amount of the above ingredients. The study emphasizes the importance of the rational selection of a combination of excipients to achieve targeted dosage form functionality.

\section{REFERENCES}

1. Prausnitz MR, Mitragotri S, Langer R. Current status and future potential of transdermal drug delivery. Nat Rev Drug Discov. 2004;3(2):115-24.

2. Ruby PK, Pathak SM, Aggarwal D. Critical attributes of transdermal drug delivery system (TDDS) - a generic product development review. Drug Dev Ind Pharm. 2014;40(11):1421-8.

3. Thomas BJ, Finnin BC. The transdermal revolution. Drug Discov Today. 2004;9(16):697-703. 
4. Paudel KS, Milewski M, Swadley CL, Brogden NK, Ghosh P, Stinchcomb AL. Challenges and opportunities in dermal/ transdermal delivery. Ther Deliv. 2010;1(1):109-31.

5. Prausnitz MR, Langer R. Transdermal drug delivery. Nat Biotechnol. 2008;26(11):1261-8.

6. Zadymova NM. Colloidochemical aspects of transdermal drug delivery (review). Colloid J. 2013;75(5):491-503.

7. Vavrova K, Zbytovska J, Hrabalek A. Amphiphilic transdermal permeation enhancers: structure-activity relationships. Curr Med Chem. 2005;12(19):2273-91.

8. Williams AC, Barry BW. Essential oils as novel human skin penetration enhancers. Int J Pharm. 1989;57(2):R7-9.

9. Patil U, Saraogi R. Natural products as potential drug permeation enhancer in transdermal drug delivery system. Arch Dermatol Res. 2014;306(5):419-26.

10. Karande P, Jain A, Ergun K, Kispersky V, Mitragotri S. Design principles of chemical penetration enhancers for transdermal drug delivery. Proc Natl Acad Sci U S A. 2005;102(13):4688-93.

11. Parikh D, Ghosh T. Feasibility of transdermal delivery of fluoxetine. AAPS PharmSciTech. 2005;6(2):E144-9.

12. Williams AC, Barry BW. Terpenes and the lipid protein partitioning theory of skin penetration enhancement. Pharm Res. 1991;8(1):17-24.

13. Gao S, Singh J. In vitro percutaneous absorption enhancement of a lipophilic drug tamoxifen by terpenes. J Control Release. 1998;51(2-3):193-9.

14. Herman A, Herman AP. Essential oils and their constituents as skin penetration enhancer for transdermal drug delivery: a review. J Pharm Pharmacol. 2015;67(4):473-85.

15. Zhao KD, Singh J. In vitro percutaneous absorption enhancement of propranolol hydrochloride through porcine epidermis by terpenes/ethanol. J Control Release. 1999;62(3):359-66.

16. Korsmeyer RW, Gurny R, Doelker E, Buri P, Peppas NA. Mechanisms of potassium chloride release from compressed, hydrophilic, polymeric matrices: effect of entrapped air. J Pharm Sci. 1983;72(10):1189-91.

17. Kusum Devi V, Saisivam S, Maria GR, Deepti PU. Design and evaluation of matrix diffusion controlled transdermal patches of verapamil hydrochloride. Drug Dev Ind Pharm. 2003;29(5):495-503.

18. Mutalik S, Udupa N. Glibenclamide transdermal patches: physicochemical, pharmacodynamic, and pharmacokinetic evaluations. J Pharm Sci. 2004;93(6):1577-94.

19. Chandak AR, Verma PRP. Development and evaluation of HPMC based matrices for transdermal patches of tramadol. Clin Res Regul Aff. 2008;25(1):13-30.

20. Kshirsagar SJ, Bhalekar MR, Mohapatra SK. Development and evaluation of carvedilol-loaded transdermal drug delivery system: in-vitro and in-vivo characterization study. Drug Dev Ind Pharm. 2012;38(12):1530-7.

21. Madan JR, Argade NS, Dua K. Formulation and evaluation of transdermal patches of donepezil. Recent pat drug delivery formulation. 2014.

22. Hayton WL, Chen T. Correction of perfusate concentration for sample removal. J Pharm Sci. 1982;71(7):820-1.

23. Barry BW. Mode of action of penetration enhancers in human skin. J Control Release. 1987;6(1):85-97.

24. Riviere A. Dose finding study of granisetron in patients receiving high-dose cisplatin chemotherapy. The Granisetron Study Group. Br J Cancer. 1994;69(5):967-71.

25. Yener G, Uuml LG, Uuml, Uuml, Ner M, et al. Design of meloxicam and lornoxicam transdermal patches: preparation, physical characterization, ex vivo and in vivo studies. Chem Pharm Bull. 2010;58(11):1466-73.

26. Khana R, Agarwal SP, Ahuja A. Preparation and evaluation of muco-adhesive buccal films of clotrimazole for oral candida infections. Indian J Pharm Sci. 1997;59(6):299-305.
27. Pinguet F, Bressolle F, Martel P, Salabert D, Astre C. Highperformance liquid chromatographic determination of granisetron in human plasma. J Chromatogr B Biomed Appl. 1996;675(1):99-105.

28. Aggarwal G, Dhawan S, Hari Kumar SL. Formulation, in vitro and in vivo evaluation of transdermal patches containing risperidone. Drug Dev Ind Pharm. 2013;39(1):39-50.

29. Greenspan L. Humidity fixed points of binary saturated aqueous solutions. J Res Nat Bur Stand Sect A. 1977;81A(1):89-96.

30. Suwanpidokkul N, Thongnopnua P, Umprayn K. Transdermal delivery of zidovudine (AZT): the effects of vehicles, enhancers, and polymer membranes on permeation across cadaver pig skin. AAPS PharmSciTech. 2004;5(3):82-9.

31. Mamatha T, Venkateswara RJ, Mukkanti K, Ramesh G. Transdermal drug delivery system for atomoxetine hydrochloride-in vitro and ex vivo evaluation. Curr Trends Biotechnol Pharm. 2009;3(2):188-96.

32. Tirunagari M, Jangala VR, Khagga M, Gannu R. Transdermal therapeutic system of isradipine: effect of hydrophilic and hydrophobic matrix on in vitro and ex vivo characteristics. Arch Pharm Res. 2010;33(7):1025-33.

33. Tanwar YS, Chauhan CS, Sharma A. Development and evaluation of carvedilol transdermal patches. Acta Pharm (Zagreb, Croatia). 2007;57:151-9.

34. Bodmeier R, Paeratakul O. Drug release from laminated polymeric films prepared from aqueous latexes. J Pharm Sci. 1990;79(1):32-6.

35. Aqil M, Ahad A, Sultana V, Ali A. Status of terpenes as skin penetration enhancers. Drug Discov Today. 2007;12(2324):1061-7.

36. Yang Z, Teng Y, Wang H, Hou H. Enhancement of skin permeation of bufalin by limonene via reservoir type transdermal patch: formulation design and biopharmaceutical evaluation. Int $\mathrm{J}$ Pharm. 2013;447(1-2):231-40.

37. Krishnaiah YS, Bhaskar P, Satyanarayana V. In vitro percutaneous permeability enhancement of nimodipine by limonene across the excised rat abdominal skin. Pharmazie. 2005;59:942-7.

38. Rowe RC, Sheskey PJ, Quinn ME. Handbook of pharmaceutical excipients. Sixth ed. Rowe RC, Sheskey PJ, Quinn ME, editors. Washington, DC: London; Greyslake, IL : Pharmaceutical Press; Washington, DC : American Pharmacists Association, 2009; 2009.

39. Ubaidulla U, Reddy MVS, Ruckmani K, Ahmad FJ, Khar RK. Transdermal therapeutic system of carvedilol: effect of hydrophilic and hydrophobic matrix on in vitro and in vivo characteristics. AAPS PharmSciTech. 2007;8(1):E13-20.

40. Madishetti SK, Palem CR, Gannu R, Thatipamula RP, Panakanti PK, Yamsani MR. Development of domperidone bilayered matrix type transdermal patches: physicochemical, in vitro and ex vivo characterization. DARU J Pharm Sci. 2010;18(3):221-9.

41. Chien YW. Development of transdermal drug delivery systems. Drug Dev Ind Pharm. 1987;13(4/5):589.

42. Costa P, Sousa Lobo JM. Modeling and comparison of dissolution profiles. Eur J Pharm Sci. 2001;13(2):123-33.

43. Chandak AR, Verma PRP. Design and development of hydroxypropyl methycellulose (HPMC) based polymeric films of methotrexate: physicochemical and pharmacokinetic evaluations. Yakugaku Zasshi. 2008;128:1057-66.

44. Prasad Verma PR, Chandak AR. Development of matrix controlled transdermal delivery systems of pentazocine: in vitro/in vivo performance. Acta Pharm (Zagreb, Croatia). 2009;59:17186.

45. Rao PR, Diwan PV. Formulation and in vitro evaluation of polymeric films of diltiazem hydrochloride and indomethacin for transdermal administration. Drug Dev Ind Pharm. 1998;24(4):327-36. 